\title{
Decoding the effect of time interval between hCG and IUI and sperm preparation and IUI
}

\author{
Smriti Agrawal*, Vinita Das, Karuna, Anjoo Agarwal, Amita Pandey, Namrata
}

Department of Obstetrics and Gynecology, King George's Medical University, Lucknow, Uttar Pradesh, India

Received: 05 February 2018

Accepted: 12 February 2018

* Correspondence:

Dr. Smriti Agrawal,

E-mail: smritijainagrawal@ rediffmail.com

Copyright: (C) the author(s), publisher and licensee Medip Academy. This is an open-access article distributed under the terms of the Creative Commons Attribution Non-Commercial License, which permits unrestricted non-commercial use, distribution, and reproduction in any medium, provided the original work is properly cited.

\begin{abstract}
Background: The study was aimed to assess the difference in IUI outcome depending on the interval between hCG trigger and IUI and sperm preparation and IUI.

Methods: The study was conducted in the Department of Obstetrics and Gynecology in Infertility unit at King George's Medical University, Lucknow from January-December 2016. All the women eligible for IUI were included in the study. Once the follicle attained size of $17-18 \mathrm{~mm}$, IUI was planned 36-48 hours after Inj. hCG 10,000 IU im. Semen processing was done in laboratory and time noted between sperm preparation and IUI. Outcome was confirmation of pregnancy by urine test. Cases were women in whom IUI was done 36-40 hours after hCG as against controls ( $>40$ hours). Interval between sperm preparation and IUI was $<30$ minutes in cases and $\geq 30$ minutes in controls.

Results: A total of 624 cycles were included in the study. Clomiphene was used in 582/624 cycles (93.3\%) gonadotropins used in $42 / 624$ cycles $(2.7 \%)$. There was a total of 23 conceptions in study $(3.7 \%)$. Of these $8 / 98$ $(8.2 \%)$ were seen when the interval between ovulation trigger and IUI was 36-40 hours and 15/526 in cycles (2.9\%) when the interval was more than 40 hours ( $\mathrm{p}=0.023$; OR-3.028 95\% CI -1.247-7.352). Of a total of 23 conceptions in the study, 18/324 conceptions were seen when IUI was done within 30 minutes of sperm preparation as compared to $5 / 300$ when interval was more than 30 minutes $(\mathrm{p}=0.01)$.

Conclusions: IUI with ovarian stimulation is a simple and effective procedure and its outcome can be maximized keeping in consideration the availability of gametes. IUI performed within 36-40 hours of hCG trigger and within 30 minutes of sperm preparation can increase conception rates.
\end{abstract}

Keywords: Case control study, IUI success, hCG trigger, Sperm processing

\section{INTRODUCTION}

Intrauterine Insemination (IUI) along with controlled ovarian stimulation has been a widely used method in management of women with infertility. IUI remains a relatively inexpensive, less invasive and easy to perform procedure, which if timed well can give favorable results. It is used in male factor infertility, minimal to mild endometriosis, PCOS, cervical factor or unexplained infertility. IUI has various determinants of success. Of these, sperm morphology, method of sperm preparation, cause of infertility, ovulation induction regime used, agent for ovulation trigger, etc. are important. Along with these, time interval between ovulation induction and IUI and time interval between sperm preparation and IUI are of definite clinical relevance.

The timing of IUI, in the majority of published studies, is 32-36 $\mathrm{h}$ following hCG administration (used for ovulation trigger). ${ }^{1}$ Cochrane review compared the different time intervals from hCG trigger to IUI ranging from 24 to 48 hours and found that there is no difference 
between groups. ${ }^{2}$ However conflicting reports in literature regarding the ideal time interval between ovulation trigger and IUI continue to confuse. . $^{3,4}$

It is postulated that prolonged time interval between sperm preparation and IUI may exhaust energy sources in processed semen thereby affecting the sperm ability to fertilize ova. It is shown that the time interval between sperm collection and IUI is to be kept as minimum as possible and preferably less than 90 minutes, but the studies are conflicting. ${ }^{5-7}$ In this institute semen collection is done at the clinic itself and semen processing is done soon after semen collection. However, there is a considerable variation in the time interval between sperm preparation and IUI. This study is aimed at identifying the difference in IUI outcome depending on the interval between hCG trigger and IUI and time interval between sperm preparation and IUI.

\section{METHODS}

The study was conducted in Infertility unit in the department of obstetrics and gynecology at King George's Medical University, Lucknow over a period of one year (January-Dececember 2016). All the women with infertility and planned for ovulation induction and IUI were enrolled in the study. The women with hyperprolactinemia (serum prolactin levels $>20 \mathrm{ng} / \mathrm{ml}$ ) and hypothyroidism (TSH $>2.5 \mu \mathrm{mIU} / \mathrm{ml}$ ) were excluded. The ovarian stimulation was done with clomiphene citrate $100 \mathrm{mg}$ or gonadotropins in appropriate doses. Serial follicular monitoring was done using transvaginal probe with GE LOGIC 5 and once the follicle attained a size of 17-18 mm, ovulation trigger was done by injection hCG 10,000 IU intramuscularly. IUI was planned 36-48 hours after trigger. Transvaginal sonography was done to assess follicular rupture.

Semen sample was collected at the clinic itself. Semen sample was prepared using swim up technique using sperm media F-10 HAM (Ham's F10 by SIGMA). If sperm quality was suboptimal, semen preparation was done by double density gradient using GRAD 80 and GRAD 40 by vitromedia. Post semen processing counts and motility were assessed and IUI was done using short IUI catheter. All the women received luteal phase support for a period of 14 days.

Time interval was noted between hCG trigger and IUI and between semen preparation and IUI. Women who had IUI within 40 hours of ovulation trigger were compared with women who had IUI after 40 hours of ovulation trigger. Comparison was also done among women who had insemination within $30 \mathrm{~min}$ of semen preparation and the women who had insemination after 30 min of semen preparation. The outcome was taken as confirmation of pregnancy by urine pregnancy test 16 days after IUI if no menstruation. If urine pregnancy test was positive, women were followed to confirm cardiac activity by tansvaginal sonography at 6 weeks.

\section{Statistical analysis}

Data were checked, entered and analyzed by using SPSS (Statistical Product and Service Solutions) version 19. Data were expressed as number and percentage for qualitative variable as pregnancy rate while they were expressed as mean $\pm \mathrm{SD}$ for quantitative variables. Chisquare (v2) test was used to compare the proportions while comparison of quantitative variables between both groups was done using Student's t-test. $\mathrm{P}<0.05$ was considered statistically significant.

\section{RESULTS}

There was a total of 624 IUI cycles in the study. Of these, 499 cycles $(80 \%)$ were of women who presented with primary infertility and 125 cycles $(20 \%)$ were of women with secondary infertility. Clomiphene was used in $582 / 624$ cycles $(93.3 \%)$ and gonadotropins were used in only 42 cycles of $624(2.7 \%)$. Various factors responsible for infertility were also noted. There were 155 (24.8\%) IUI cycles in women with ovulatory factor, 189 (30.2\%) cycles with tubal factor, and 200 cycles $(32.2 \%)$ with unexplained infertility. Eighty cycles $(2.8 \%)$ had male factor as the cause of infertility.

Table 1: Demographic variables among case and controls on the basis of time interval between ovulation trigger and IUI.

\begin{tabular}{|c|c|c|c|}
\hline $\begin{array}{l}\text { Demographic } \\
\text { variable }\end{array}$ & $\begin{array}{l}\text { Cases } \\
\text { ( } \leq 40 \text { hours) } \\
n=98\end{array}$ & $\begin{array}{l}\text { Controls } \\
(>40 \text { hours) } \\
n=526\end{array}$ & $\begin{array}{l}\text { P } \\
\text { value }\end{array}$ \\
\hline Mean age (years) & $29.4 \pm 4.5$ & $29.6 \pm 4.2$ & 0.729 \\
\hline Primary infertility & $76(77.5 \%)$ & $423(80.4 \%)$ & \multirow[b]{2}{*}{0.607} \\
\hline $\begin{array}{l}\text { Secondary } \\
\text { infertility }\end{array}$ & $22(22.4 \%)$ & $103(19.5 \%)$ & \\
\hline \multicolumn{4}{|l|}{ Type of infertility } \\
\hline Ovulatory & $21(21.4 \%)$ & $134(25.4 \%)$ & 0.469 \\
\hline Male & $14(14.2 \%)$ & $66(12.5 \%)$ & 0.758 \\
\hline Tubal & $30(30.6 \%)$ & $159(30.2 \%)$ & 0.939 \\
\hline Unexplained & $33(33.6 \%)$ & $167(31.7 \%)$ & 0.797 \\
\hline Clomiphene & $93(94.9 \%)$ & $489(92.9 \%)$ & \multirow{2}{*}{0.630} \\
\hline Gonadotropins & $5(5.1 \%)$ & $37(7.01 \%)$ & \\
\hline
\end{tabular}

Women were serially monitored by transvaginal ultrasound and ovulation trigger was given by administering injection hCG 10,000 once the follicle attained a diameter of $17-18 \mathrm{~mm}$. The time interval between hCG trigger and IUI was noted and cases were taken as cycles when the interval was less than or 40 hours and controls if the interval was more than 40 hours. There were 98 cases and 526 controls in the study. Demographic variables were studied in both groups and are shown in Table 1. There were a total of 23 conceptions noted in the study $(3.7 \%)$. Of these $8 / 98$ $(8.2 \%)$ were seen in cycles when the interval between ovulation trigger and IUI was $\leq 40$ hours and $15 / 526$ in cycles $(2.9 \%)$ when the interval was more than 40 hours $(\mathrm{p}=0.023$; OR-3.028 95\% CI -1.247-7.352). 
Table 2: Demographic variables among case and controls on the basis of time interval between sperm preparation and IUI.

\begin{tabular}{|c|c|c|c|}
\hline $\begin{array}{l}\text { Demographic } \\
\text { variable }\end{array}$ & $\begin{array}{l}\text { Cases } \\
(<30 \text { min }) \\
n=324\end{array}$ & $\begin{array}{l}\text { Controls } \\
(>\mathbf{3 0} \text { min }) \\
\mathbf{n}=\mathbf{3 0 0}\end{array}$ & $\begin{array}{l}P \\
\text { value }\end{array}$ \\
\hline Mean age (years) & $29.54 \pm 4.16$ & $29.65 \pm 4.35$ & 0.747 \\
\hline Primary infertility & 259(79.9\%) & $240(80 \%)$ & \multirow[b]{2}{*}{0.996} \\
\hline $\begin{array}{l}\text { Secondary } \\
\text { infertility }\end{array}$ & $65(20.1 \%)$ & $60(20 \%)$ & \\
\hline \multicolumn{4}{|l|}{ Type of infertility } \\
\hline Ovulatory & $81(25 \%)$ & $74(24.6 \%)$ & 0.997 \\
\hline Male & $41(12.6 \%)$ & $39(13 \%)$ & 0.992 \\
\hline Tubal & $92(28.3 \%)$ & $97(32.3 \%)$ & 0.325 \\
\hline Unexplained & $110(33.9 \%)$ & $90(30 \%)$ & 0.331 \\
\hline Clomiphene & $290(89.5 \%)$ & $292(97.3 \%)$ & \multirow{2}{*}{0.0002} \\
\hline Gonadotropins & $34(10.5 \%)$ & $8(2.7 \%)$ & \\
\hline
\end{tabular}

Results were also compared in 2 groups depending on the time interval between sperm preparation and IUI. Cases were defined as cycles in which IUI was done within 30 minutes of sperm preparation and controls were when IUI was done after 30 minutes of sperm preparation. There were 324 cycles among cases and 300 cycles in control group. Demographic variables like age, type of infertility, factors of infertility, type of ovulation induction agent used is shown in Table 2.

Of a total of 23 conceptions in the study, 18/324 conceptions were seen in cases when IUI was done within 30 minutes of sperm preparation as compared to $5 / 300$ in controls when IUI was done more than 30 minutes after sperm preparation $(\mathrm{p}=0.01)$.

Among 23 women who conceived, swim up technique was used in 11 women and double density gradient in 12 women. The number of women who received gonadotropins was much higher in group where IUI was done within 30 minutes of sperm preparation. However, there was no difference in conception rate as only 2 women who received gonadotropins conceived.

\section{DISCUSSION}

IUI along with ovarian stimulation is a relatively cost effective method and hence considered as a first line management of subfertile couples. Among the various determinants of IUI success, two important determinants are studied here- the interval between hCG and IUI and the time interval between sperm preparation and IUI. Factors including age, type of infertility and cause of infertility were similar in both groups.

Though documentation of ovulation was not done, effort was made to exact the time interval of IUI. In this study it was seen that if IUI was performed within 40 hours after hCG, conceptions were more as compared to when IUI was delayed beyond 40 hours. There are conflicting reports in literature regarding optimal timing of IUI in relation to hCG. It is usually recommended that IUI should be performed 32-36 hours following hCG administration. A prospective randomized trial by Rahman and colleagues showed conflicting results. This study enrolled 204 couples with mild male factor, unexplained infertility, and mild endometriosis who underwent 461 IUI- COS cycles and were randomized to two groups: Group I (IUI 36 hours after hCG) and Group II (IUI 24 hours after hCG). The result displayed that patients who underwent IUI 36 hours after hCG had marginally better pregnancy rates than the 24 hour group, although without statistical significance. ${ }^{8}$ On the contrary, several studies showed similar pregnancy rates whether IUI was done 24 hours, 36 hours or 48 hours following hCG.9-11

Yumusak et al also showed similar conception rates in 24 or 36 hour interval in PCOS patients; however IUI in unexplained infertility showed better results when done 24 hours after hCG. ${ }^{12}$ However, Kamel et al in a study conducted in Egypt in couples with unexplained infertility studied the different timings of IUI in relation to hCG trigger. The author found that there was a significant increase in pregnancy rate (up to $22.6 \%$ ) when IUI was done 48 hours after hCG trigger as compared to only $10.6 \%$ when done at 36 hours. The authors suggested that if IUI is delayed by 48 hours, there is better secretory endometrium while not compromising oocyte viability and hence more chances of conception. There was however significantly higher mean number of follicles in this group that could have led to higher pregnancy rate. ${ }^{3}$ Similar finding was also noted by Soliman who demonstrated better conception rates with IUI after 48 hours of hCG. ${ }^{4}$ Moreover, the Cochrane review provided no evidence of a difference in pregnancy rates based upon varying IUI timing ranging from 24 to 48 hours after hCG injection and stated that there is insufficient evidence to determine whether there is any difference in effectiveness between different synchronized approaches for IUI in sub fertile couples. ${ }^{2}$

Kucuk performed IUI 36-38 hours following hCG and stated in his study that more than timing, documentation of ovulation improves the success of IUI. In the women where ovulation was evident, clinical pregnancy rate was $23.5 \%$ as compared to only $8.1 \%$ when follicle rupture was not seen $(\mathrm{p}<0.001) .{ }^{13}$ Ghanem et al also timed IUI as per ovulation and concluded that single IUI timed post ovulation had better outcome as compared to IUI done preovulation. ${ }^{14}$ Since there are many conflicting reports in literature and the intervals compared are also dissimilar, it is difficult to conclude the impact of interval of hCG trigger with IUI outcome. In the absence of documentation of ovulation, this study however reasonably concluded that IUI timed within 40 hours after hCG trigger had better outcome than later.

Optimal time interval between sperm preparation and IUI remains controversial. A Turkish hospital assessed the interval between sperm preparation and IUI and showed 
that lowest pregnancy rates were observed when IUI was performed within 30 minutes of sperm preparation as compared to when done from 30- 180 minutes $(\mathrm{p}=0.01)$. The authors postulated that sperms after preparation when allowed to stand at $37 \mathrm{C}$ for a longer interval (>30 minutes) undergoes better in vitro capacitation leading to better conception rates. ${ }^{15}$ Alexander et al studied only clomiphene treated cycles and stated that there was no difference in pregnancy outcome in respect to time interval between sperm preparation and IUI.

However, it is also thought that prolonged sperm preparation and IUI interval can lead to reduced fertilizing ability of spermatozoa due to exhaustion of energy sources in sperm washing medium and premature in vitro capacitation making them ineffective. In order to optimize IUI outcome, it is suggested that the time interval between sperm preparation and IUI is to be kept at minimum. This study also showed that IUI performed within 30 minutes of semen preparation yielded better results.

Koyun et al studied semen parameters at 30, 60, and 90 minutes interval after sperm preparation and concluded that semen parameters are negatively affected by prolonged incubation time $(\mathrm{p}<0.005)$ and IUI if done within 60 minutes of semen preparation may increase pregnancy rates. ${ }^{7}$ Yavas et al in a study in 2004 found that the interval of sperm collection to sperm wash, sperm wash-IUI and collection-IUI interval were shorter in pregnant than non pregnant women when treated with HMG. IUI performed within 90 minutes of semen collection led to higher pregnancy rates than IUI performed more than 90 minutes later in women treated with HMG and not clomiphene cycles. ${ }^{16}$

IUI with ovarian stimulation is a simple and effective procedure and its outcome can be maximized keeping in consideration the availability of gametes. If IUI is performed 36-40 hours of hCG trigger and within 30 minutes of sperm preparation, it was found in present study that conception rates can be significantly increased. This study is limited by small number of conceptions noted; hence it was difficult to analyze the determinants effectively.

The number of women who received gonadotropins was much higher in group where IUI was done within 30 minutes of sperm preparation. However, there was no difference in conception rate as only 2 women who received gonadotropins conceived implying that conception rate was not affected by either method of ovulation induction. A larger randomized trial to assess the effect of hCG trigger and sperm preparation-IUI interval will help in demystifying the optimum intervals to achieve the best success rates.

Funding: No funding sources Conflict of interest: None declared

Ethical approval: Not required

\section{REFERENCES}

1. ESHRE Capri Workshop Group. Intrauterine Insemination. Hum Reprod update. 2009;1(1):1-13.

2. Cantineau AE, Janssen MJ, Cohlen BJ, Allersma T. Synchronised approach for intrauterine insemination in subfertile couples. Cochrane Data Syst Rev. 2014;12:CD006942.

3. Kamel AM, Hussien AM, Salah E. The effect of delaying intrauterine insemination till $48 \mathrm{~h}$ after hCG injection on pregnancy rate. Middle East Fertil Soc J. 2015;20:290-4.

4. Soliman BS. Effect of time interval between human chorionic gonadotropin injection and intrauterine insemination on pregnancy rate. Middle East Fertil Soc J. 2016;21:222-7.

5. Gautam AN. Does the time interval between semen collection, processing and intrauterine insemination affects results of IUI. J Obstet Gynecol India. 2009;59(5):407- 9 .

6. Alexander CJ, King J, Lipari C, Zhao Y, Wallach EE. The effect of time intervals between semen collection, processing and intrauterine insemination (IUI) on pregnancy rates in clomiphene-citrate-IUI Cycles. Fertil Steril. 2005;84:S279.

7. Koyun E, Okyay RE, Dogan OE, Koval M, Dogan $\mathrm{SS}$, Guleki B. The effect of intrauterine insemination time on semen parameters. J Turk Ger Gynecol Assoc. 2014;15:82-5.

8. Rahman SM, Karmakar D, Malhotra N, Kumar S. Timing of intrauterine insemination: an attempt to unravel the enigma. Arch Gynecol Obstet. 2011;284:1023e7.

9. Aboul Gheit S. Pregnancy rates following three different timings of intrauterine insemination for women with unexplained infertility: a randomised controlled trial. Middle East Fertil Soc J. 2010;15:265-8.

10. Wang YC, Chang YC, Chen IC, Cnien HH, Wu GJ. Comparison of timing of IUI in ovarian stimulated cycles. Arch Androl. 2006;52:371-4.

11. Huang FJ, Chang SY, Lu YJ, Kung FT, Tsai MY, Wu JF. Two different timings of intrauterine insemination for non-male infertility. J Assist Reprod Genet. 2000;17:213e7.

12. Yumusak OH, Kahyaoglu S, Pekcan MK, Isci E, Cinar M, Tasci Y. Does intrauterine insemination timing matter for achievement of pregnancy during ovulation induction by using gonadotropins? A retrospective cohort study. J Chin Med Assoc. 2017 Jun 1;80(6):366-70.

13. Kucuk T. Intrauterine insemination: is the timing correct? J Assist Reprod Genet. 2008;25:427-30.

14. Ghanem ME, Bakre NI, Emam MA, Boghdady LA, Helal AS, Elmetwally AG, et al. The effects of timing of intrauterine insemination in relation to ovulation and the number of inseminations on cycle pregnancy rate in common infertility etiologies. Human Reprod. 2011;26(3):576-83. 
15. Kilicdag EB. The effect of intervals from sperm preparation to intra uterine insemination (IUI) time on pregnancy rate. J Turk Soc Obstet Gynecol. 2012;9(3):159-63.

16. Yavas Y, Selub MR. Intrauterine insemination (IUI) pregnancy outcome is enhanced by shorter intervals from semen collection to sperm preparation, from sperm preparation to IUI time, and from semen collection to IUI time. Fertil Steril. 2004;82(6):163847.

Cite this article as: Agrawal S, Das V, Karuna, Agarwal A, Pandey A, Namrata. Decoding the effect of time interval between hCG and IUI and sperm preparation and IUI. Int J Reprod Contracept Obstet Gynecol 2018;7:892-6. 